Responses to sexual advances and satisfaction in romantic relationships: Is yes good and no bad?

Kiersten Dobson ${ }^{1}$, Jenney Zhu ${ }^{1}$, Rhonda N. Balzarini ${ }^{2}$, \& Lorne Campbell ${ }^{1}$

${ }^{1}$ University of Western Ontario

${ }^{2}$ York University

Author Note

Kiersten Dobson is a Ph.D. candidate in the Department of Psychology at the University of Western Ontario.

Jenney Zhu recently received her BA in Psychology from the University of Western Ontario.

Rhonda N. Balzarini is a postdoctoral fellow in the Department of Psychology at York University.

Lorne Campbell is a Professor in the Department of Psychology at the University of Western Ontario.

This research was supported in part by a Canada Graduate Scholarship awarded to Kiersten Dobson from the Social Sciences and Humanities Research Council (SSHRC) of Canada and a grant awarded to Lorne Campbell from SSHRC.

Please address correspondence to Kiersten Dobson; E-mail: kdobson8@uwo.ca 


\begin{abstract}
We examine the relations between accepting and rejecting a partner's sexual advances with sexual and relationship satisfaction, and assess how long these effects endure. Couples $(N=115)$ completed a 21-day daily diary indicating whether a partner made a sexual advance each day, and if so, whether the advance was accepted or rejected. Having one's sexual advance accepted was associated with increased sexual and relationship satisfaction that day, and increased sexual satisfaction up to 24 hours later. Having one's sexual advance rejected was associated with decreased sexual satisfaction that day and up to 48 hours later. Sexual advances made by one's partner were associated with increased sexual satisfaction that day and for up to 72 hours later, regardless of whether the advance was accepted or rejected. Findings indicate benefits of sexual activity, but also prolonged post-rejection decreases in sexual satisfaction.
\end{abstract}

Keywords: Romantic Relationships; Sexuality; Interpersonal Relationships; Hierarchical Linear Modeling/Multilevel Modeling 


\section{Responses to sexual advances and satisfaction in romantic relationships: Is yes good and no bad?}

Sexuality and the expectation of engaging in sexual activity are defining features of romantic relationships and have become increasingly important to one's satisfaction and happiness over the last several decades (Schwartz \& Young, 2009). Sexual activity and satisfaction are associated with several benefits for romantic relationships, including increased relationship satisfaction, love, commitment, and pair bonding (e.g. Birnbaum \& Finkel, 2015; Meston \& Buss, 2007; Sprecher, 2002). Romantic couples typically engage in sexual activity 1-2 times per week (e.g. Byers \& Heinlein, 1989; Vannier \& O’Sullivan, 2011), however sexual advances are made an average of 3-4 times per week (Byers \& Heinlein, 1989). Among relationship partners, therefore, approximately half of weekly sexual advances will be accepted and the other half rejected.

\section{Responses to Sexual Advances and Satisfaction}

Accepting a partner's sexual advance or having one's advance accepted by a partner is typically associated with benefits to the self and the relationship, including feeling more attractive, promoting intimacy, and increasing sexual satisfaction (Dosch, Rochat, Ghisletta, Favez \& Van der Linden, 2016; Koch, Mansfield, Thurau \& Carey, 2005; Yoo, Bartle-Haring, Day, \& Gangamma, 2014). Recent research has shown that engaging in sexual activity with a romantic partner is not only associated with increased sexual satisfaction on that day, but the effects endured for up to 48 hours, which the authors termed the sexual afterglow effect (Meltzer, Makhanova, Hicks, French, McNulty, \& Bradbury, 2017). However, this research only recruited newlyweds, which limits its generalizability, and only accounted for the presence or absence of sexual activity, and not which partner made the advance, which partner responded, or whether 
the lack of sexual activity was due to sexual rejection. That is, the absence of sexual activity could be the result of neither partner making a sexual advance that day, or one partner sexually rejecting the other. These researchers therefore grouped together a neutral experience (i.e. no sexual activity when no advance was made) with an inherently negative one (i.e. no sexual activity because of rejection) to comprise their neutral comparison point, potentially exaggerating the positive benefits of sexual activity. The current research addresses these limitations in sample and study design, and replicates and extends this research by simultaneously examining the relations between sexual acceptance, sexual rejection, and satisfaction in a heterogenous community sample of romantic couples.

Although there may be benefits to accepting a partner's sexual advance, not all sexual advances are accepted. There is some evidence that more frequent sexual rejection is associated with lower sexual and relationship satisfaction. Byers and Heinlein (1989) found that married and/or cohabiting undergraduates whose relationships involved a greater frequency of negative responses to sexual initiations (i.e. sexual rejections) over a one-week period were less sexually satisfied, and male participants were also less relationally satisfied. Recent research, however, examining the association between sexual rejection and sexual and relationship satisfaction found that sexual rejection characterized by reassurance (e.g. reassuring your partner that you love them, are attracted to them, etc.) was not associated with lower relationship satisfaction, but was negatively associated with sexual satisfaction (Kim, Muise, \& Impett, 2018). Nevertheless, discrepancies between relationship partners on the desired frequency of sexual activity is one of the most frequently cited problems among romantic couples (Risch, Riley \& Lawler, 2003), indicating a need for greater understanding of the experience and consequences of when sexual activity does not occur (i.e. sexual rejection). Additionally, the limited research regarding sexual 
rejection has examined its effects globally and has not yet teased apart the experience of being sexually rejected from being the rejecter, a limitation that is also addressed in the current research.

\section{Current Research}

The present research simultaneously assessed the association between responses to sexual advances (both acceptance and rejection) and sexual and relationship satisfaction. Specifically, we hypothesized that instances of having one's sexual advance accepted or accepting one's partner's advance (i.e., when sexual activity occurs) should result in higher than baseline sexual and relationship satisfaction, consistent with previous research (e.g., Meltzer et al., 2017). In contrast, consistent with previous research (e.g., Byers \& Heinlein, 1989; Kim et al., 2018), instances of having one's sexual advance rejected should lead to lower than baseline levels of sexual satisfaction. The relation between having one's advance rejected and relationship satisfaction was examined as well, however, given contradictory evidence for this association these analyses were exploratory.

Additionally, as sexual discrepancies are a frequently cited issue in romantic relationships (Risch et al., 2003), experiencing sexual rejection may be associated with decreased satisfaction, regardless of whether one is the rejecter or the rejected. The rejecter in sexual situations may experience negative emotions such as guilt, similar to rejecters in situations of unrequited love (Baumeister \& Dhavale, 2001). However, receiving a sexual advance is associated with feeling more attractive and desired by one's partner (Dodrill, 2007; Pease, 2013), which may promote greater satisfaction regardless of whether one rejects the requester. Therefore, we also explored the relation between rejecting one's partner's advances and satisfaction. 
Finally, the current research addresses some of the limitations of Meltzer and colleagues' (2017) work, and replicates and extends this research by examining how long satisfaction may remain increased following acceptance of a sexual advance and decreased following rejection. Consistent with the sexual afterglow effect we anticipated that the benefits of sexual acceptance would last 48 hours, and proposed that the adverse effects of sexual rejection would last a similar amount of time. ${ }^{1}$ At the request of our reviewers, we have created a table summarizing all of our original hypotheses, indicate whether they are the focus of the current paper, and whether they were supported (see Table 1).

\footnotetext{
${ }^{1}$ The preregistration for this research can be accessed at https://osf.io/ctq4m. A description of all hypotheses, materials, syntax, and results of this study are available at https://osf.io/pjwsf/. Deidentified data has been privately stored on the OSF; access to the data is available upon request (email: kdobson8@uwo.ca).
} 
Table 1. Summary of Hypotheses

\begin{tabular}{|c|c|c|c|}
\hline \multicolumn{2}{|c|}{ Hypothesis } & $\begin{array}{l}\text { Focus of the } \\
\text { current paper? }\end{array}$ & Supported? \\
\hline \multirow{3}{*}{$\begin{array}{l}\text { Having one's sexual advance } \\
\text { accepted will be associated with }\end{array}$} & Higher sexual satisfaction that day & Yes & Yes \\
\hline & $\begin{array}{l}\text { Higher relationship satisfaction that } \\
\text { day }\end{array}$ & Yes & Yes \\
\hline & $\begin{array}{l}\text { Higher sexual satisfaction up to } 48 \\
\text { hours later }\end{array}$ & Yes & Partially \\
\hline \multirow{3}{*}{$\begin{array}{l}\text { Accepting a sexual advance from } \\
\text { one's partner will be associated with }\end{array}$} & Higher sexual satisfaction that day & Yes & Yes \\
\hline & $\begin{array}{l}\text { Higher relationship satisfaction that } \\
\text { day }\end{array}$ & Yes & Yes \\
\hline & $\begin{array}{l}\text { Higher sexual satisfaction for up to } \\
48 \text { hours later }\end{array}$ & Yes & Yes \\
\hline \multirow{3}{*}{$\begin{array}{l}\text { Having one's sexual advance } \\
\text { rejected will be associated with }\end{array}$} & Lower sexual satisfaction that day & Yes & Yes \\
\hline & Relationship satisfaction that day* & Yes & $\mathrm{N} / \mathrm{A}$ \\
\hline & $\begin{array}{l}\text { Lower sexual satisfaction for up to } \\
48 \text { hours later }\end{array}$ & Yes & Partially \\
\hline \multirow[t]{2}{*}{$\begin{array}{l}\text { Rejecting an advance from one's } \\
\text { partner will be associated with }\end{array}$} & $\begin{array}{l}\text { Sexual satisfaction that day, and on } \\
\text { subsequent days* }\end{array}$ & Yes & N/A \\
\hline & $\begin{array}{l}\text { Relationship satisfaction that day, } \\
\text { and on subsequent days* }\end{array}$ & Yes & N/A \\
\hline \multirow{2}{*}{$\begin{array}{l}\text { Trust will moderate the effect of } \\
\text { being sexually rejected, such that } \\
\text { higher trust will be associated with a } \\
\text { smaller magnitude of the effect of } \\
\text { rejection on }\end{array}$} & Sexual satisfaction & No & No \\
\hline & Relationship satisfaction & No & Yes \\
\hline \multirow{2}{*}{$\begin{array}{l}\text { Relationship security will moderate } \\
\text { the effect of being sexually rejected, } \\
\text { such that higher security will be } \\
\text { associated with a smaller magnitude } \\
\text { of the effect of rejection on }\end{array}$} & Sexual satisfaction & No & No \\
\hline & Relationship satisfaction & No & No \\
\hline \multirow{2}{*}{$\begin{array}{l}\text { Gender will moderate the effect of } \\
\text { being sexually rejected, such that } \\
\text { women will experience a stronger } \\
\text { negative effect of sexual rejection } \\
\text { than men on }\end{array}$} & Sexual satisfaction & No & No \\
\hline & Relationship satisfaction & No & No \\
\hline
\end{tabular}

Note: * indicates exploratory analyses

\section{Methods}




\section{Participants and Procedure}

The target sample size was 100 couples (200 individuals) after accounting for attrition and failure to meet inclusion criteria. This sample is consistent with previous studies using similar methodologies (e.g. Hagemeyer, Schönbrodt, Neyer, Neberich, \& Asendorpf, 2015; Meltzer et al., 2017), but includes more diary days (21 days versus 14 days), and allows for 4200 potential data points. Participants consisted of 130 cohabiting, heterosexual romantic couples recruited through online advertisements (e.g., Kijiji, Facebook), an email list of couples who previously participated in our research, and flyers posted around the London, Ontario community. Data from 15 couples were excluded because one or both partners did not consent to participate in the study $(n=5)$ or did not meet inclusion criteria $(n=4$ non-monogamous, $n=1$ same-sex couple, $n=1$ does not speak/read English fluently, $n=4$ one or both partners did not complete at least 3 diary surveys), resulting in a final sample of 115 couples. Partners ranged from 19-64 years of age $\left(M_{\text {years }}=30.78, S D_{\text {years }}=8.99\right)$ and had been together between 5 months and 25.58 years $\left(M_{\text {years }}=6.83, S D_{\text {years }}=5.87\right)$. Among participants, $41.74 \%$ of couples were dating, and 58.26\% were common-law, engaged, or married.

Participant responses were collected online via the survey software Qualtrics, and survey links were automatically sent to participants at a pre-set time of their choosing (typically evenings). Participants were instructed to complete all surveys, including a 30-minute background survey, 10-minute daily surveys for 21 consecutive days, and a 30-minute post-diary survey, independently from their partner. Reminder emails were automatically sent to the participants who had not completed their diary within three hours of their start time each day to maximize participant compliance. On average, participants completed 18.87 diaries across the 21-day study (range $=4-21$ ) for a total of 4339 diary surveys completed across all participants. 
Compensation for this study was pro-rated; participants could earn $\$ 2$ each for taking the background and post-diary questionnaires, $\$ 1$ for each daily survey, and a $\$ 10$ bonus for contributing to all study elements, for a maximum of $\$ 35$ per person. This research protocol was approved by Western University's non-medical research ethics board.

\section{Measures}

The current research only uses responses to the 21-day daily diary portion of the study, where we used shortened versions of the focal measures to reduce fatigue, increase efficiency, and minimize participant attrition (Bolger, Davis, \& Rafaeli, 2003). We report within-person reliability of our measures (reliability of change, $R c$ ).

Responses to Sexual Advances. Each day, participants were asked to indicate whether they made a sexual advance towards their partner, and if so, whether it led to sexual activity. Additionally, participants were asked to report whether their partner made a sexual advance towards them, and if so, whether that advance led to sexual activity. We then created 4 dummy coded variables for responses to sexual advances, with "no advance was made" as the reference category: 1) accepted (the participant made a sexual advance that led to sexual activity), 2) rejected (the participant made a sexual advance that did not lead to sexual activity), 3) accepter (the participant's partner made a sexual advance that led to sexual activity), and 4) rejecter (the participant's partner made a sexual advance that did not lead to sexual activity).

Sexual Satisfaction. Three items from the Global Measure of Sexual Satisfaction (GMSEX; Lawrance \& Byers, 1998) asked participants to indicate on 7-point bipolar scales which best describes their daily sexual relationship: unsatisfying-satisfying, unpleasant-pleasant, and good-bad. Items were mean aggregated with higher scores indicating higher sexual satisfaction $(R c=.96, M=4.93, S D=1.81)$. 
Relationship Satisfaction. Participants responded to four items from Hendrick's (1988)

relationship satisfaction scale on a 5-point scale $(1=$ not at all/extremely poor, $5=$ a great

deal/extremely good) regarding how satisfied they were with their relationship each day (e.g.,

"How satisfied are you with your relationship?", "How good is your relationship compared to most?"). Items were mean aggregated with higher scores indicating higher relationship satisfaction $(R c=.80, M=4.42, S D=.71)$.

\section{Results}

\section{Post-Advance Changes in Satisfaction}

To test whether acceptance or rejection of sexual advances were associated with satisfaction, we conducted two-level crossed models with random intercepts where persons are nested within dyads, and person and days are crossed to account for the fact that both partners completed the daily surveys on the same days (Kenny, Kashy, \& Cook, 2006). As all couples are heterosexual (and therefore individuals nested in couples can be identified by their gender), we have distinguishable dyads. We used an ARH1 error structure to model the correlation between participants' current outcome (i.e. satisfaction) and the outcome value that immediately preceded it (i.e. the previous day's satisfaction) to account for the fact that observations that are closer in time are more similar to each other than observations that are further apart. ${ }^{2}$ The dummy coded variables for responses to sexual advances were then simultaneously entered as predictors of

\footnotetext{
${ }^{2}$ We preregistered a three-level model with days nested within individuals nested within couples to be consistent with the methods of Meltzer and colleagues (2017). However, a further review of the literature brought to our attention that the use of a three-level model when partners completed the measures on the same days has a number of statistical problems (e.g. Kenny, Kashy, \& Cook, 2006) and is not recommended. We therefore amended the analytic plan and preregistered the current two-level crossed models where persons are nested within dyads, and person and days are crossed to account for the fact that both partners completed the daily surveys on the same days (Kenny et al., 2006). We also opted for a heterogeneous first-order autoregressive (ARH1) covariance structure rather than the heterogeneous compound symmetry (CSH) specified in our original plan to account for the fact that observations that are closer in time are more similar to each other than observations that are further apart. The original preregistration can be found at https://osf.io/sp6f8.
} 
daily sexual and relationship satisfaction, resulting in the following level 1 equation in a twolevel model:

$Y t i=\pi 0 i+\pi 1 i$ (accepted the same day) $+\pi 2 i$ (rejected the same day) $+\pi 3 i$ (accepter the same day) $+\pi 4 i$ (rejecter the same day) $+e t i$

where Yti refers to individual $i$ 's satisfaction at time $t$, the day of the diary entry, and $\pi 0 i$ is the intercept. Day of diary entry and relationship length (covariates added in additional models) were grand-mean-centered, and the sexual advance status variables and effect-coded gender (an additional covariate) were uncentered.

Sexual satisfaction. Results are presented in Table 2. Having a sexual advance accepted, being the accepter, and being the rejecter positively predicted sexual satisfaction that day. However, having a sexual advance rejected by one's partner was negatively associated with sexual satisfaction. These associations held when controlling for gender, relationship length, and day of diary entry.

Relationship satisfaction. Results are presented in Table 3. Having one's sexual advance accepted and accepting one's partner's advance (accepter) were associated with greater relationship satisfaction. However, neither having a sexual advance rejected by one's partner nor being the rejecter were significantly associated with relationship satisfaction. These associations held when controlling for gender, relationship length, and day of diary entry.

\section{How Long do Post-Advance Changes in Satisfaction Last?}

Lagged MLM analyses were conducted to determine the length of time sexual advance status may be associated with satisfaction. In these models we estimated the residual matrix by nesting partner within couple*day satisfaction with an ARH1 structure, and lagged the dummy coded variables for sexual advance status to see if the previous day's status impacted each day's 
satisfaction, while accounting for that day's sexual advance status, and couple level satisfaction (average for that couple across all days).

For example, we first examined the extent to which sexual advance status on a given day predicts satisfaction 24 hours later by estimating the following lagged Level 1 equation in a twolevel model:

$Y t i=\pi 0 i+\pi 1 i($ accepted 1 day prior $)+\pi 2 i($ rejected 1 day prior $)+\pi 3 i$ (accepter 1 day prior $)+$ $\pi 4 i$ (rejecter 1 day prior) $+\pi 5 i$ (accepted that day) $+\pi 6 i$ (rejected that day) $+\pi 7 i$ (accepter that day) $+\pi 8 i$ (rejecter that day) $+e t i$

where Yti refers to individual $i$ 's satisfaction at time $t$, the day of the diary entry, and $\pi 0 i$ is the intercept. Day of diary entry and relationship length (covariates added in additional models) were grand-mean-centered, and the sexual advance status variables were uncentered. In the second model we examined the extent to which sexual advance status on a given day predicted satisfaction 48 hours later by estimating the following lagged Level 1 equation in a two-level model with the same specifications:

$Y t i=\pi 0 i+\pi 1 i$ (accepted 2 days prior) $+\pi 2 i$ (rejected 2 days prior) $+\pi 3 i$ (accepter 2 days prior) $+\pi 4 i$ (rejecter 2 days prior) $+\pi 5 i$ (accepted 1 day prior) $+\pi 6 i$ (rejected 1 day prior $)+\pi 7 i$ (accepter 1 day prior) $+\pi 8 i$ (rejecter 1 day prior) $+\pi 9 i$ (accepted that day) $+\pi 10 i$ (rejected that day) $+\pi 11 i$ (accepter that day) $+\pi 12 i$ (rejecter that day) $+e t i$

We then explored additional models using the same specifications for the effects 72 and 96 hours later, until the effects were no longer significant.

Sexual satisfaction. Results from these analyses are presented in Table 2, and all effects of sexual advance status held when controlling for gender, relationship length, and day of diary entry. Daily sexual satisfaction was positively associated with having an advance accepted the 
previous day, being the rejecter the previous day, and marginally associated with being the accepter the previous day, controlling for sexual advance status that day. Additionally, having an advance rejected the previous day was negatively associated with sexual satisfaction that day. These results suggest that, consistent with previous research, post-acceptance changes in satisfaction (i.e. sexual afterglow) last at least 24 hours, however post-rejected changes in sexual satisfaction last at least 24 hours as well. 
Table 2. Results of Models Testing the Effects of Responses to Sexual Advances on Immediate and Lingering Sexual Satisfaction

\begin{tabular}{|c|c|c|c|c|c|c|c|c|c|c|c|c|c|c|c|}
\hline \multirow[b]{2}{*}{ Predictor } & \multicolumn{3}{|c|}{ Same-day effect } & \multicolumn{3}{|c|}{ 24-hour effect } & \multicolumn{3}{|c|}{ 48-hour effect } & \multicolumn{3}{|c|}{ 72-hour effect } & \multicolumn{3}{|c|}{ 96-hour effect } \\
\hline & $b$ & $S E$ & $R^{2}$ & $b$ & $S E$ & $R^{2}$ & $b$ & $S E$ & $R^{2}$ & $b$ & $S E$ & $R^{2}$ & $b$ & $S E$ & $R^{2}$ \\
\hline Intercept & -.39 & .10 & & -.43 & .10 & & -.48 & .11 & & -.55 & .11 & & -.59 & .11 & \\
\hline Accepted the same day & $1.12 * * *$ & .05 & .138 & $1.22 * * *$ & .06 & .104 & $1.22 * * *$ & .06 & .102 & $1.26 * * *$ & .07 & .111 & $1.28 * * *$ & .07 & .114 \\
\hline Rejected the same day & $-.15 *$ & .06 & .002 & $-.31 * * *$ & .07 & .005 & $-.26 * * *$ & .08 & .003 & $-.23 * *$ & .08 & .003 & $-.25 * *$ & .09 & .003 \\
\hline Accepter the same day & $.94 * * *$ & .05 & .092 & $1.0 * * *$ & .06 & .065 & $1.00 * * *$ & .06 & .066 & $1.00 * * *$ & .07 & .065 & $.99 * * *$ & .07 & .067 \\
\hline Rejecter the same day & $.30 * * *$ & .07 & .006 & $.41 * * *$ & .08 & .007 & $.38 * * *$ & .09 & .006 & $.36 * * *$ & .09 & .005 & $.35 * * *$ & .10 & .005 \\
\hline Accepted 1 day prior & & & & $.12 *$ & .06 & .001 & $.14^{*}$ & .06 & .001 & $.14^{*}$ & .07 & .001 & $.13^{+}$ & .07 & .001 \\
\hline Rejected 1 day prior & & & & $-.30 * * *$ & .07 & .005 & $-.23 * *$ & .08 & .003 & $-.18 *$ & .08 & .002 & -.14 & .09 & .001 \\
\hline Accepter 1 day prior & & & & $.10^{+}$ & .06 & .001 & $.14 *$ & .07 & .001 & $.13 *$ & .07 & .001 & $.18 * *$ & .07 & .002 \\
\hline Rejecter 1 day prior & & & & $.25 * *$ & .08 & .003 & $.26 * *$ & .09 & .003 & $.27 * *$ & .09 & .003 & $.26 * *$ & .09 & .003 \\
\hline Accepted 2 days prior & & & & & & & .05 & .06 & $<.001$ & .04 & .06 & $<.001$ & .07 & .07 & $<.001$ \\
\hline Rejected 2 days prior & & & & & & & $-.22 * *$ & .08 & .003 & $-.24 * *$ & .08 & .003 & $-.22 *$ & .09 & .003 \\
\hline Accepter 2 days prior & & & & & & & $.18 * *$ & .06 & .002 & $.18^{* *}$ & .07 & .002 & $.20 * *$ & .07 & .003 \\
\hline Rejecter 2 days prior & & & & & & & $.22 * *$ & .08 & .002 & $.22 *$ & .09 & .002 & $.21 *$ & .10 & .002 \\
\hline Accepted 3 days prior & & & & & & & & & & .06 & .06 & $<.001$ & .06 & .07 & $<.001$ \\
\hline Rejected 3 days prior & & & & & & & & & & -.12 & .08 & .001 & $-.14^{+}$ & .08 & .001 \\
\hline Accepter 3 days prior & & & & & & & & & & $.15^{*}$ & .07 & .002 & $.15^{*}$ & .07 & .002 \\
\hline Rejecter 3 days prior & & & & & & & & & & $.18 *$ & .09 & .001 & .12 & .09 & .001 \\
\hline Accepted 4 days prior & & & & & & & & & & & & & $.11^{+}$ & .07 & .001 \\
\hline Rejected 4 days prior & & & & & & & & & & & & & -.13 & .08 & .001 \\
\hline Accepter 4 days prior & & & & & & & & & & & & & .08 & .07 & $<.001$ \\
\hline Rejecter 4 days prior & & & & & & & & & & & & & $.15^{+}$ & .09 & .001 \\
\hline
\end{tabular}

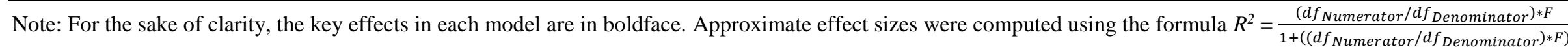
(Edwards, Muller, Wolfinger, Qaqish, \& Schabenberger, 2008; Page-Gould, 2016).

${ }^{+} p \leq .10$. $* p \leq .05 . * * p \leq .01$. ***p $\leq .001$. 
Table 3. Results of Models Testing the Effects of Responses to Sexual Advances on Immediate and Lingering Relationship Satisfaction

\begin{tabular}{|c|c|c|c|c|c|c|c|c|c|c|c|c|}
\hline \multirow[b]{2}{*}{ Predictor } & \multicolumn{3}{|c|}{ Same-day effect } & \multicolumn{3}{|c|}{ 24-hour effect } & \multicolumn{3}{|c|}{ 48-hour effect } & \multicolumn{3}{|c|}{ 72-hour effect } \\
\hline & $b$ & $S E$ & $R^{2}$ & $b$ & $S E$ & $R^{2}$ & $b$ & $S E$ & $R^{2}$ & $b$ & $S E$ & $R^{2}$ \\
\hline Intercept & .01 & .05 & & -.02 & .05 & & -.02 & .05 & & -.02 & .06 & \\
\hline Accepted the same day & $.05 * * *$ & .01 & .006 & $.08 * * *$ & .02 & .005 & $.08 * * *$ & .02 & .006 & $.08 * * *$ & .02 & .005 \\
\hline Rejected the same day & -.02 & .02 & $<.001$ & $-.07 * *$ & .02 & .003 & $-.06 *$ & .03 & .002 & $-.06^{*}$ & .03 & .002 \\
\hline Accepter the same day & $.04 * *$ & .01 & .002 & $.04 *$ & .02 & .001 & $.05 *$ & .02 & .001 & $.05 *$ & .02 & .002 \\
\hline Rejecter the same day & .03 & .02 & .001 & $.06^{*}$ & .03 & .001 & .03 & .03 & $<.001$ & .01 & .03 & $<.001$ \\
\hline Accepted 1 day prior & & & & .02 & .02 & $<.001$ & .02 & .02 & $<.001$ & .02 & .02 & $<.001$ \\
\hline Rejected 1 day prior & & & & $-.07 * *$ & .02 & .003 & $-.05^{+}$ & .02 & .001 & -.04 & .03 & .001 \\
\hline Accepter 1 day prior & & & & .01 & .02 & $<.001$ & .02 & .02 & $<.001$ & .02 & .02 & $<.001$ \\
\hline Rejecter 1 day prior & & & & .02 & .03 & $<.001$ & $<.01$ & .03 & $<.001$ & $<.01$ & .03 & $<.001$ \\
\hline Accepted 2 days prior & & & & & & & .01 & .02 & $<.001$ & $<-.01$ & .02 & $<.001$ \\
\hline Rejected 2 days prior & & & & & & & $-.08 * *$ & .02 & .004 & $-.07 * *$ & .03 & .003 \\
\hline Accepter 2 days prior & & & & & & & .03 & .02 & $<.001$ & .04 & .02 & .001 \\
\hline Rejecter 2 days prior & & & & & & & $.08 * *$ & .03 & .002 & $.07 * *$ & .03 & .002 \\
\hline Accepted 3 days prior & & & & & & & & & & $<-.01$ & .02 & $<.001$ \\
\hline Rejected 3 days prior & & & & & & & & & & $-.05 *$ & .03 & .002 \\
\hline Accepter 3 days prior & & & & & & & & & & -.01 & .02 & $<.001$ \\
\hline Rejecter 3 days prior & & & & & & & & & & $.06 *$ & .03 & .001 \\
\hline
\end{tabular}

Note: For the sake of clarity, the key effects in each model are in boldface. Approximate effect sizes were computed using the formula $R^{2}=$ $\left(d f_{\text {Numerator }} / d f_{\text {Denominator }}\right) * F$

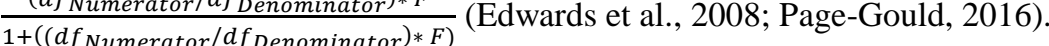

${ }^{+} p \leq .10 . * p \leq .05 . * * p \leq .01$. ***p $\leq .001$. 
In the second model, daily sexual satisfaction was positively predicted by being the rejecter two days prior and with being the accepter two days prior. However, having one's sexual advance accepted two days prior was not significantly associated with sexual satisfaction. Additionally, having one's sexual advance rejected two days prior was negatively associated with sexual satisfaction. Taken together, these results suggest that post-accepted changes in sexual satisfaction may only last 24 hours, but having ones' partner make an advance (whether accepted or rejected) and post-rejected changes in sexual satisfaction may last at least 48 hours.

In the third model, daily sexual satisfaction was significantly positively predicted by being the rejecter two days prior and being the accepter two days prior, but was not significantly associated with being accepted or rejected. Finally, in the fourth model, none of the sexual advance status variables significantly predicted sexual satisfaction. Together, results of these models indicate post-rejected changes in sexual satisfaction may only last 48 hours, but having ones' partner make an advance (whether accepted or rejected) may last 72 hours, but not 96 hours.

Relationship satisfaction. Results from these analyses are presented in Table 3. Daily relationship satisfaction was not associated with being accepted, being the rejecter, or being the accepter the previous day, but was negatively associated with having an advance rejected the previous day, controlling for sexual advance status that day. We believe these results should be interpreted with caution, as being rejected on a given day was not significantly associated with that day's relationship satisfaction in the original model, and the lagged effects of being rejected were nearing non-significance when controlling for gender, relationship length, and day of diary entry $(p=.044)$. Therefore, there may be post-rejected changes in relationship satisfaction 24 hours after the rejection occurred, but this finding would strongly benefit from replication. We 
present the findings for two additional lagged models with relationship satisfaction in Table 3 , as there were significant effects in the 48-hour lagged model (the effects in the 72-hour model did not hold when controlling for gender, relationship length, and day of diary entry). However, we do not interpret the significant effects given the inconsistency with previous models.

\section{Sexual Afterglow Effect}

For comparison, we sought to replicate the sexual afterglow effect (Meltzer et al., 2017) examining the association of sexual activity versus no sexual activity with sexual satisfaction while disregarding which partner made the advance and which responded, as well as whether a lack of sexual activity was due to no advances being made or sexual rejection occurring. We used the same modeling procedures described above, but used the presence of sexual activity as a predictor rather than the sexual advance status variables, and included day of diary entry as a predictor to be consistent with Meltzer and colleagues (2017). Results are summarized in Table 4. When only examining the effects of sexual activity versus no activity, sexual activity was associated with increased sexual satisfaction that day and for up to five days afterwards, and these results held when controlling for gender and relationship length.

Although Meltzer and colleagues (2017) did not examine the effects of sexual activity on immediate and lingering relationship satisfaction, we also include those results for comparison to our previous models. Results are summarized in Table 5. When only examining the effects of sexual activity versus no activity, sexual activity was associated with increased relationship satisfaction that day and for up to one day afterwards. Results for effects the day of and for one day afterwards held when controlling for gender and relationship length, but results for two days afterwards became significant when controlling for these variables.

\section{Additional Results From Original Preregistration and Moderation Analyses}


At the editor's request, we include a summary below of the results of the three-level models and the moderation analyses included in our original preregistration. We include the summary but not statistics for the three-level models as these models have a number of statistical problems (e.g. Kenny et al., 2006). However, full details of all results can be found at https://osf.io/n2jtk/.

In the three-level model, having your sexual advance accepted, accepting your partner's advance, and rejecting your partner's advance predicted increased sexual satisfaction that day, while having your sexual advance rejected by your partner predicted decreased sexual satisfaction that day. Additionally, sexual satisfaction on a given day was positively associated with having your advance accepted the previous day, rejecting your partner's advance the previous day, and marginally associated with accepting your partner's advance the previous day, and marginally negatively associated with having your advance rejected the previous day. Sexual satisfaction was not associated with sexual advance status from two days prior. In the three-level model, none of the sexual advance status variables predicted significant differences in daily relationship satisfaction.

In the three-level moderation models, gender moderated the association between sexual satisfaction and accepting your partner's advance, with this boost to sexual satisfaction being higher in women than in men. Trust did not significantly moderate the relation between any of the four sexual advance status variables and sexual satisfaction. Relationship security moderated the association between rejecting one's partner's advance and sexual satisfaction. None of the three moderators significantly moderated the associations between the sexual advance status variables and relationship satisfaction. 
In the two-level moderation models, the interactions between daily trust and having one's advance accepted, and trust and accepting one's partner's advance on daily sexual satisfaction were significant. Although these associations were significant and positive in all cases, the effects were stronger for those with lower trust than those with higher trust. The interactions between daily trust and being accepted, being rejected, and being the rejecter on relationship satisfaction were also significant. None of the effects of these predictors on relationship satisfaction were significant when trust was high, but when trust was low being accepted and being the rejecter were positively associated with relationship satisfaction, while being rejected was negatively associated with relationship satisfaction. Results of all two-level moderation models are summarized in Table 6.

Additionally, the interactions between security and being the accepter on sexual satisfaction, security and being accepted on relationship satisfaction, and security and being the rejecter on relationship satisfaction were significant. Although when security was high being the accepter was significantly positively associated with sexual satisfaction, this effect was stronger when security was low. When security was high neither being accepted nor being the rejecter were associated with relationship satisfaction, but when security was low both of these variables were positively associated with relationship satisfaction.

Finally, gender significantly moderated the associations between being accepted and sexual satisfaction, and being the accepter and sexual satisfaction. The association between being accepted and sexual satisfaction was stronger for men than women, and the association between being the accepter and sexual satisfaction was stronger for women than men, although in all cases the association was significant and positive. Gender did not significantly moderate the associations between any of the sexual advance status variables and relationship satisfaction. 
Table 4. Results of Models Testing the Effects of Sexual Activity on Immediate and Lingering Sexual Satisfaction

\begin{tabular}{|c|c|c|c|c|c|c|c|c|c|c|c|c|c|c|c|c|c|c|c|c|c|}
\hline \multirow[b]{2}{*}{ Predictor } & \multicolumn{3}{|c|}{ Same-day effect } & \multicolumn{3}{|c|}{ 24-hour effect } & \multicolumn{3}{|c|}{ 48-hour effect } & \multicolumn{3}{|c|}{ 72-hour effect } & \multicolumn{3}{|c|}{ 96-hour effect } & \multicolumn{3}{|c|}{ 120-hour effect } & \multicolumn{3}{|c|}{ 144-hour effect } \\
\hline & $b$ & $S E$ & $R^{2}$ & $b$ & $S E$ & $R^{2}$ & $b$ & $S E$ & $R^{2}$ & $b$ & $S E$ & $R^{2}$ & $b$ & $S E$ & $R^{2}$ & $b$ & $S E$ & $R^{2}$ & $b$ & $S E$ & $R^{2}$ \\
\hline Intercept & $-.41 * * * *$ & .10 & & $-.51 * * *$ & .10 & & $-.54 * * *$ & .11 & & $-.61 * * *$ & .11 & & $-.63^{* * * *}$ & .11 & & $-.68 * * *$ & .12 & & $-.69 * * *$ & .12 & \\
\hline Day of diary entry & $<.01$ & $<.01$ & & $<-.01$ & $<.01$ & & -.01 & $<.01$ & & -.01 & $<.01$ & & -.01 & $<.01$ & & -.01 & .01 & & -.01 & .01 & \\
\hline Sex the same day & $1.57 * * *$ & .04 & .343 & $1.70 * * *$ & .06 & .402 & $1.68^{* * *}$ & .05 & .397 & $1.70 * * *$ & .05 & .399 & $1.70 * * *$ & .05 & .400 & $1.68 * * *$ & .05 & .410 & $1.71^{* * *}$ & .06 & .417 \\
\hline Sex 1 day prior & & & & $.25 * * *$ & .05 & .014 & $.26 * * *$ & .05 & .016 & $.25 * * *$ & .05 & .015 & $.28 * * *$ & .05 & .018 & $.26 * * *$ & .05 & .016 & $.29 * * *$ & .06 & .020 \\
\hline Sex 2 days prior & & & & & & & $.16 * * *$ & .003 & .006 & $.18 * * *$ & .05 & .008 & $.18 * * *$ & .05 & .007 & $.19 * * *$ & .05 & .009 & $.15^{* *}$ & .06 & .005 \\
\hline Sex 3 days prior & & & & & & & & & & $.17 * * *$ & .05 & .007 & $.17 * * *$ & .05 & .007 & $.19 * * *$ & .05 & .009 & $.22 * * *$ & .06 & .012 \\
\hline Sex 4 days prior & & & & & & & & & & & & & $.13 * *$ & .05 & .004 & $.13 * *$ & .05 & .005 & $.14 * *$ & .06 & .005 \\
\hline Sex 5 days prior & & & & & & & & & & & & & & & & $.18 * * * *$ & .05 & .008 & $.19 * * *$ & .05 & .009 \\
\hline Sex 6 days prior & & & & & & & & & & & & & & & & & & & .06 & .05 & .001 \\
\hline
\end{tabular}

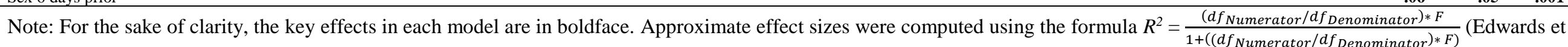
al., 2008; Page-Gould, 2016).

${ }^{+} p \leq .10 .{ }^{*} p \leq .05 . * * p \leq .01 .{ }^{* * *} p \leq .001$.

Table 5. Results of Models Testing the Effects of Sexual Activity on Immediate and Lingering Relationship Satisfaction

\begin{tabular}{|c|c|c|c|c|c|c|c|c|c|}
\hline \multirow[b]{2}{*}{ Predictor } & \multicolumn{3}{|c|}{ Same-day effect } & \multicolumn{3}{|c|}{ 24-hour effect } & \multicolumn{3}{|c|}{ 48-hour effect } \\
\hline & $b$ & $S E$ & $R^{2}$ & $b$ & $S E$ & $R^{2}$ & $b$ & $S E$ & $R^{2}$ \\
\hline Intercept & .01 & .05 & & $-.03^{+}$ & .05 & & -.03 & .05 & \\
\hline Day of diary entry & $<.01 *$ & $<.01$ & & $<.01$ & $<.01$ & & $<.01$ & $<.01$ & \\
\hline Sex the same day & $.07 * * *$ & .01 & .018 & $.10 * * *$ & .01 & .025 & $.10 * * *$ & .01 & .030 \\
\hline Sex 1 day prior & & & & $.03 *$ & .01 & .003 & $.03 *$ & .01 & .003 \\
\hline Sex 2 days prior & & & & & & &. $\mathbf{0 3}^{+}$ & .01 & .002 \\
\hline
\end{tabular}

Note: For the sake of clarity, the key effects in each model are in boldface. Approximate effect sizes were computed using the formula $R^{2}=$

$\frac{\left(d f_{\text {Numerator }} / d f_{\text {Denominator }}\right) * F}{1+\left(\left(d f_{\text {Numerator }} / d f_{\text {Denominator }}\right) * F\right)}($ Edwards et al., 2008; Page-Gould, 2016).

$1+\left(\left(d f_{\text {Numerator }} / d f_{\text {Denominator }}\right) * F\right)$
${ }^{+} p \leq .10 . * p \leq .05 . * * p \leq .01 . * * * p \leq .001$ 
Table 6. Results of Two-level Moderation Models

\begin{tabular}{|c|c|c|c|c|c|}
\hline Outcome & Predictor & Simple slopes & $b$ & $S E$ & $R^{2}$ \\
\hline \multirow{22}{*}{ Sexual satisfaction } & Accepted*Trust & & $-.14 *$ & .06 & .002 \\
\hline & & High trust & $.98 * * *$ & .07 & .056 \\
\hline & & Low trust & $1.24 * * *$ & .08 & .091 \\
\hline & Rejected*Trust & & .06 & .07 & $<.001$ \\
\hline & Accepter*Trust & & $-.14 *$ & .06 & .002 \\
\hline & & High trust & $.81 * * *$ & .07 & .037 \\
\hline & & Low trust & $1.08 * * *$ & .08 & .059 \\
\hline & Rejecter*Trust & & .07 & .08 & .001 \\
\hline & Accepted*Security & & -.12 & .06 & .001 \\
\hline & Rejected*Security & & -.06 & .07 & $<.001$ \\
\hline & Accepter*Security & & $-.20 * * *$ & .06 & .004 \\
\hline & & High security & $.77 * * *$ & .07 & .033 \\
\hline & & Low security & $1.14 * * *$ & .08 & .068 \\
\hline & Rejecter*Security & & .07 & .09 & $<.001$ \\
\hline & Accepted $*$ Gender & & $-.15^{* *}$ & .05 & .003 \\
\hline & & Men & $1.20 * * *$ & .06 & .165 \\
\hline & & Women & $.99 * * *$ & .07 & .090 \\
\hline & Rejected*Gender & & .04 & .06 & $<.001$ \\
\hline & Accepter*Gender & & $.20 * * *$ & .05 & .005 \\
\hline & & Men & $.74 * * *$ & .07 & .054 \\
\hline & & Women & $1.13 * * *$ & .07 & .128 \\
\hline & Rejecter*Gender & & -.11 & .07 & .001 \\
\hline \multirow[t]{22}{*}{ Relationship satisfaction } & Accepted*Trust & & $-.04 * *$ & .01 & .004 \\
\hline & & High trust & .01 & .02 & $<.001$ \\
\hline & & Low trust & $.08 * * *$ & .02 & .010 \\
\hline & Rejected*Trust & & $.05^{* *}$ & .02 & .004 \\
\hline & & High trust & .01 & .02 & $<.001$ \\
\hline & & Low trust & $-.09 * * *$ & .02 & .006 \\
\hline & Accepter*Trust & & -.01 & .01 & $<.001$ \\
\hline & Rejecter*Trust & & $-.07 * * *$ & .02 & .008 \\
\hline & & High trust & -.04 & .03 & .001 \\
\hline & & Low trust & $.10 * * *$ & .03 & .006 \\
\hline & Accepted*Security & & $-.04 * *$ & .02 & .003 \\
\hline & & High security & -.004 & .02 & $<.001$ \\
\hline & & Low security & $.07 * * *$ & .02 & .006 \\
\hline & Rejected*Security & & .02 & .02 & .001 \\
\hline & Accepter*Security & & .02 & .02 & $<.001$ \\
\hline & Rejecter*Security & & $-.06 *$ & .02 & .003 \\
\hline & & High security & -.03 & .03 & $<.001$ \\
\hline & & Low security & $.08 * *$ & .03 & .003 \\
\hline & Accepted*Gender & & -.02 & .01 & .001 \\
\hline & Rejected*Gender & & .02 & .02 & .001 \\
\hline & Accepter*Gender & & .02 & .01 & .001 \\
\hline & Rejecter*Gender & & -.01 & .02 & $<.001$ \\
\hline
\end{tabular}

Note: Separate models were run for each moderator. We report only the interaction terms, but models also included main effects. When an interaction is statistically significant, we report the results of simple slopes analyses below it. $* * * p \leq .001 * * p \leq .01 * p \leq .05$ 


\section{Discussion}

Consistent with hypotheses, having one's sexual advance accepted was associated with increased sexual and relationship satisfaction that day. This is also consistent with previous research, as having one's sexual advance accepted indicates both that sexual activity occurred, which is associated with a number of relationship benefits (e.g. Birnbaum \& Finkel, 2015), and that acceptance was offered by one's partner, which is also a positive relationship experience (Baumeister \& Leary, 1995). Additionally, having one's advance accepted was associated with increased sexual satisfaction 24 hours after the advance was made, consistent with the sexual afterglow effect reported by Meltzer et al. (2017), but was not found for the full 48 hours as was reported in this prior research. Although we found positive effects across various relationships and sexual encounters, we also note there are situations in which sexual acceptance is harmful (e.g. sexual coercion and sexual compliance; Katz \& Myhr, 2008; Katz \& Tirone, 2009).

In contrast, having one's sexual advance rejected was associated with decreased sexual satisfaction that day, consistent with past literature demonstrating that rejection by one's partner is painful (Leary, Springer, Negel, Ansell, \& Evans, 1998), particularly sexual rejection (Byers \& Heinlein, 1989; Kim et al., 2018). Also, as predicted, being sexually rejected was associated with lower sexual satisfaction for 48 hours after the rejection occurred. In combination with our previous findings, this indicates that when one makes an advance the benefits of being accepted are high, but the costs of being rejected may be longer-lasting. This novel finding is corroborated by a wide variety of psychological findings in other areas demonstrating that negative experiences have a greater impact than positive experiences (for reviews, see Rozin \& Royzman, 2001; Baumeister, Bratslavsky, Finkenauer, \& Vohs, 2001). These results indicate that making a sexual advance may be risky for romantic partners, which may lead those who feel less sure of 
their partner's response to an advance to do so less often, therefore missing opportunities to bolster intimacy, closeness, and satisfaction. Additionally, some individuals may respond more positively to being sexually rejected by a romantic partner than others (Muise, Kim, Impett, \& Rosen, 2017), indicating future research examining whether particular individuals may experience greater benefits or detriments of sexual acceptance and rejection is warranted.

We found inconsistent effects regarding the association between being sexually rejected and relationship satisfaction, as it was not significantly associated with relationship satisfaction that day, but was associated with relationship satisfaction for up to 48 hours after the rejection occurred. However, we note that these inconsistent results for relationship satisfaction are representative of the past literature. For example, Byers and Heinlein (1989) found that more frequent rejection of sexual advances was associated with lower relationship satisfaction, but Kim and colleagues (2018), who examined a specific type of sexual rejection characterized by reassurance, did not find this effect. Given this inconsistency, we do not interpret these effects in our study and recommend replication to determine the robustness of these findings.

Finally, contrary to the idea that sexually rejecting one's partner may be a negative experience resulting in emotions such as guilt, but consistent with research demonstrating that receiving a sexual advance is associated with feeling more attractive and desired by one's partner (Dodrill, 2007; Pease, 2013), one's partner making a sexual advance appears to promote greater satisfaction for oneself regardless of whether it is accepted or declined. In particular, both being the accepter and being the rejecter were associated with increased sexual satisfaction that day. Interestingly, these effects also appear to last the longest, with being the accepter and being the rejecter both being associated with increased sexual satisfaction for up to 72 hours after the advance was made. One explanation for this may be that being the "sexual gatekeeper", or the 
partner who consistently receives sexual advances and sets the limits on when sexual activity occurs, may be associated with higher sexual satisfaction. However, as women are traditionally the sexual gatekeepers in heterosexual relationships, this proposition is inconsistent with previous findings demonstrating that women are generally equally or less sexually satisfied than men (e.g. Colson, Lemaire, Pinton, Hamidi, \& Klein, 2006; Haavio-Mannila \& Kontula, 1997; Waite \& Joyner, 2001). Therefore, future research may benefit from examining the mechanisms behind the positive and lasting effects of having one's partner make a sexual advance.

One limitation of the current study is that many of the effects, although statistically significant, are small, and that the number of tests conducted increased the likelihood of a Type I error. The largest effect sizes in our analyses emerged when examining sexual satisfaction on days when sexual activity occurred, either through the partner accepting the individual's advance (accepted) or through the individual accepting their partner's advance (accepter). Given the small effect sizes of the remaining effects, we recommend replication. Additionally, although we sought to recruit a more diverse sample than Meltzer and colleagues' (2017) study, we encourage future researchers to examine these effects in samples not covered by this previous research or by the current study, such as same-sex couples or couples who do not live together.

\section{Conclusion}

Sexual advances in romantic relationships and partners' responses to them have unique and meaningful associations with sexual and relationship satisfaction. In response to the question "Is yes "good" and no "bad"?," our results suggest that yes is consistently good, and has enduring positive effects. However, our findings indicate that no could be good or bad depending on your role as the rejecter or the rejected. We found positive associations with satisfaction for the rejecter and negative associations with satisfaction for the rejected, with both associations 
enduring over multiple days. The present research furthers existing knowledge on sexual activity, a defining feature of romantic relationships, and the implications it has for partners' satisfaction.

\section{Author Contributions}

Kiersten Dobson developed the study concept and study design. Data collection was performed by Kiersten Dobson and Jenney Zhu. Kiersten Dobson performed the data analysis and interpretation. Kiersten Dobson drafted the manuscript, and Jenney Zhu, Rhonda Balzarini, and Lorne Campbell provided critical revisions. All authors approved the final version of the manuscript for submission. 


\section{References}

Baumeister, R. F., Bratslavsky, E., Finkenauer, C., \& Vohs, K. D. (2001). Bad is stronger than good. Review of General Psychology, 5, 323-370.

Baumeister, R. F., \& Dhavale, D. (2001). Two sides of romantic rejection. In M. R. Leary (Ed.), Interpersonal rejection (pp. 55-71). New York, NY: Oxford University Press.

Baumeister, R. F., \& Leary, M. R. (1995). The need to belong: desire for interpersonal attachments as a fundamental human motivation. Psychological Bulletin, 117, 497-529.

Birnbaum, G. E., \& Finkel, E. J. (2015). The magnetism that holds us together: Sexuality and relationship maintenance across relationship development. Current Opinion in Psychology, 1, 29-33.

Bolger, N., Davis, A., \& Rafaeli, E. (2003). Diary methods: Capturing life as it is lived. Annual Review of Psychology, 54, 579-616. doi:10.1146/annurev.psych.54.101601.145030

Byers, E. S., \& Heinlein, L. (1989). Predicting initiations and refusals of sexual activities in married and cohabiting heterosexual couples. The Journal of Sex Research, 26, 210-231. doi:10.1080/00224498909551507

Carlsen, E., Petersen, J. H., Andersson, A. M., \& Skakkebaek, N. E. (2004). Effects of ejaculatory frequency and season on variations in semen quality. Fertility and Sterility, 82, 358-366.

Colson, M. H., Lemaire, A., Pinton, P., Hamidi, K. and Klein, P. (2006). Sexual behaviors and mental perception, satisfaction and expectations of sex life in men and women in France. Journal of Sex Medicine, 3, 121-131. 
Dodrill, W. (2007). Sexual initiation in ongoing heterosexual dating relationships (Doctoral dissertation). Retrieved from ProQuest Dissertations and Theses (Dissertation No. 3243475).

Dosch, A., Rochat, L., Ghisletta, P., Favez, N., \& Van der Linden, M. (2016). Psychological factors involved in sexual desire, sexual activity, and sexual satisfaction: A multifactorial perspective. Archives of Sexual Behavior, 45, 2029-2045. doi:10.1007/s10508014-0467-z

Edwards, L. J., Muller, K. E., Wolfinger, R. D., Qaqish, B. F., \& Schabenberger, O. (2008). An $\mathrm{R}^{2}$ statistic for fixed effects in the linear mixed model. Statistics in Medicine, 27, 61376157.

Hagemeyer, B., Schönbrodt, F. D., Neyer, F. J., Neberich, W., \& Asendorpf, J. B. (2015). When "together" means "too close": Agency motives and relationship functioning in coresident and living-apart-together couples. Journal of Personality and Social Psychology, 109, 813-835.

Haavio-Mannila, E. \& Kontula, O. (1997). Correlates of increased sexual satisfaction. Archives of Sexual Behavior, 26, 399-419.

Hendrick, S. S. (1988). A generic measure of relationship satisfaction. Journal of Marriage and Family, 50, 93-98.

Katz, J., \& Myhr, L. (2008). Perceived conflict patterns and relationship quality associated with verbal sexual coercion by male dating partners. Journal of Interpersonal Violence, 23, 798-814. 
Katz, J., \& Tirone, V. (2009). Women's sexual compliance with male dating partners: Associations with investment in ideal womanhood and romantic well-being. Sex Roles, 60, 347-356.

Kenny, D. A., Kashy, D. A, \& Cook, W. L. (2006). Dyadic data analysis. New York, NY: Guildford Press.

Kim, J., Muise, A., \& Impett, E. A. (2018). The relationship implications of rejecting a partner for sex kindly versus having sex reluctantly. Journal of Social and Personal Relationships, 35, 485-508. doi:10.1177/0265407517743084

Koch, P. B., Mansfield, P. K., Thurau, D., \& Carey, M. (2005). "Feeling frumpy": The relationships between body image and sexual response changes in midlife women. Journal of Sex Research, 42, 215-223. doi:10.1080/00224490509552276

Lawrance, K., \& Byers, E. S. (1998). Interpersonal Exchange Model of Sexual Satisfaction Questionnaire. In C. M. Davis, W. L. Yarber, R. Baureman, G. Schreer, \& S. L. Davis (Eds.), Sexuality related measures: A compendium (2nd ed., pp. 514-519). Thousand Oaks, CA: Gage.

Leary, M. R., Springer, C., Negel, L., Ansell, E., \& Evans, K. (1998). The causes, phenomenology, and consequences of hurt feelings. Journal of Personality and Social Psychology, 74, 1225-1237. doi:http://dx.doi.org/10 .1037/0022-3514.74.5.1225

Meltzer, A. L., Makhanova, A., Hicks, L. L., French, J. E., McNulty, J. K., \& Bradbury, T. N. (2017). Quantifying the sexual afterglow: The lingering benefits of sex and their implications for pair-bonded relationships. Psychological Science, 28, 587-598. doi:10.1177/0956797617691361 
Meston, C. M., \& Buss, D. M. (2007). Why humans have sex. Archives of Sexual Behavior, 36, 477-507.

Muise, A., Kim, J. J., Impett, E. A., \& Rosen, N. O. (2017). Understanding when a partner is not in the mood: Sexual communal strength in couples transitioning to parenthood. Archives of Sexual Behavior, 46, 1993-2006.

Muise, A., Schimmack, U., \& Impett, E. A. (2016). Sexual frequency predicts greater well-being, but more is not always better. Social Psychological and Personality Science, 7, 295-302.

Murray, S. L., Rose, P., Bellavia, G. M., Holmes, J. G., \& Kusche, A. G. (2002). When rejection stings: How self-esteem constrains relationship-enhancement processes. Journal of Personality and Social Psychology, 83, 556-573. doi:10.1037//0022-3514.83.3.556

Page-Gould, E. (2016, May). Elegant multilevel modeling. Invited workshop presented at the annual meeting of the Association of Psychological Science, Chicago, IL, US.

Pease, L. J. (2013). What did you do last night?: How sharing hookup narratives impacts friendships and displays status among college women (Thesis). Retrieved from Dickinson Scholar Honors Theses (Paper 64).

Risch, G. S., Riley, L. A., \& Lawler, M. G. (2003). Problematic issues in the early years of marriage: Content for premarital education. Journal of Psychology and Theology, 31, 253-269. doi:10.1177/009164710303100310

Rozin, P., \& Royzman, E. B. (2001). Negativity bias, negativity dominance, and contagion. Personality and Social Psychology Review, 5, 296-320.

Schwartz, P., \& Young, L. (2009). Sexual satisfaction in committed relationships. Sexuality Research and Social Policy, 6, 1-17. doi:10.1525/srsp.2009.6.1.1 
Sprecher, S. (2002). Sexual satisfaction in premarital relationships: Associations with satisfaction, love, commitment, and stability. Journal of Sex Research, 39, 190-196. doi:10.1080/00224490209552141

Vannier, S. A., \& O'Sullivan, L. F. (2011). Communicating interest in sex: Verbal and nonverbal initiation of sexual activity in young adults' romantic dating relationships. Archives of Sexual Behavior, 40, 961-969.

Waite, L. J., \& Joyner, K. (2001). Emotional and physical satisfaction with sex in married, cohabiting, and dating sexual unions: Do men and women differ? In E. O. Laumann \& R. T. Michael (Eds.), Sex, love, and health in America: Private choices and public policies (pp. 239-269). Chicago, IL: University of Chicago Press.

Yoo, H., Bartle-Haring, S., Day, R. D., \& Gangamma, R. (2014). Couple communication, emotional and sexual intimacy, and relationship satisfaction. Journal of Sex and Marital Therapy, 40, 275-293. doi:10.1080/0092623X.2012.751072 